\title{
Ultralong free-standing single crystal perovskite microwires with extremely low dark current
}

\section{Xiangshun Geng ( $\sim$ gengxiangsh@163.com )}

Tsinghua University

\section{Qi-Xin Feng}

Tsinghua University

\section{He Tian}

Tsinghua University

\section{Weijian Chen}

Swinburne University of Technology https://orcid.org/0000-0001-8394-2391

\section{Xiaoming Wen}

Swinburne University of Technology

\section{Baohua Jia}

Swinburne University of Technology https://orcid.org/0000-0002-6703-477X

\section{Chaolun Wang}

East China Normal University

\section{Xing Wu}

East China Normal University

\section{Guan-Hua Dun}

Tsinghua University

Jun Ren

Tsinghua University

\section{Ningqin Deng}

Tsinghua University

\section{Fangwei Wang}

Tsinghua University

\section{Zhaoyi Yan}

Tsinghua University

\section{Hainan Zhang}

Tsinghua University

\section{Cheng Li}

Beihang University

\section{Yi Yang}

Institute of Microelectronics \& Tsinghua National Laboratory for Information Science and Technology (TNList), Tsinghua University 


\section{Dan Xie}

Tsinghua University

Tian-Ling Ren

Tsinghua University https://orcid.org/0000-0002-7330-0544

\section{Article}

Keywords: super long perovskite microwires, dark current, single crystal

Posted Date: June 16th, 2021

DOl: https://doi.org/10.21203/rs.3.rs-629456/v1

License: (c) (1) This work is licensed under a Creative Commons Attribution 4.0 International License. Read Full License 


\section{Ultralong free-standing single crystal perovskite microwires with extremely low dark current}

Xiangshun Geng ${ }^{1}$, Qixin Feng ${ }^{1}$, He Tian ${ }^{1}{ }^{*}$, Weijian Chen $^{2}$, Xiaoming $\mathrm{Wen}^{2}$, Baohua $\mathrm{Jia}^{2}$, Chaolun Wang ${ }^{3}$, Xing $\mathrm{Wu}^{3}$, Guanhua Dun ${ }^{1}$, Jun Ren ${ }^{1}$, Ningqin Deng ${ }^{1}$, Fangwei Wang ${ }^{1}$, Zhaoyi Yan ${ }^{1}$, Hainan Zhang ${ }^{1}$, Cheng $\mathrm{Li}^{4}$, Yi Yang ${ }^{1, *}$, Dan Xie ${ }^{1, *}$, Tian-Ling Ren ${ }^{1, *}$

${ }^{1}$ School of Integrated Circuits and Beijing National Research Center for Information Science and Technology (BNRist), Tsinghua University, Beijing 100084, China;

${ }^{2}$ Centre for Translational Atomaterials, School of Science, Swinburne University of Technology, Hawthorn Victoria 3122, Australia;

${ }^{3}$ Shanghai Key Laboratory of Multidimensional Information Processing, School of Communication and Electronic Engineering, East China Normal University, 500 Dongchuan Road, Shanghai, 200241, China.

${ }^{4}$ School of Instrumentation Science and Opto-Electronics Engineering, Beihang University, Beijing 100191, China.

”Email: Rentl@tsinghua.edu.cn, tianhe88@tsinghua.edu.cn, yiyang@tsinghua.edu.cn, xiedan@tsinghua.edu.cn

Abstract-Super long perovskite microwires (PMWs) are in a great demand in many fields such as low-loss microcables and integrated optical waveguide. Despite decades of research into PMWs, single crystal PMWs with several centimeters long have not been obtained. Here, ultralong (up to 7.6 centimeters) monoclinic crystal structure $\mathrm{CH}_{3} \mathrm{NH}_{3} \mathrm{PbI}_{3} \cdot \mathrm{DMF}^{\mathrm{PMW}}$ have been synthesized. The high-quality microwire exhibits long carrier lifetime of $1775.7 \mathrm{~ns}$. The as-prepared free-standing PMWs can be integrated to any arbitrary substrate and $808 \mathrm{~nm}$ nearinfrared photodetectors have been successfully demonstrated. The fabricated device shows a high light on/off ratio of $1.79 \times 10^{6}$ and an extremely low dark current of $2.5 \mathrm{fA}$ at $1 \mathrm{~V}$ bias. This work provides a strategy for the solution growth of ultralong microwires.

\section{Introduction}

Since the perovskite has been widely used in solar cells ${ }^{1}$, there has been a great interest in the production and processing of lead halide perovskites due to their large absorption coefficients ${ }^{2}$, high carrier mobilities and carrier diffusion lengths ${ }^{3-5}$. In general, single crystal perovskite nano/microwires with well-defined crystal structures have very low defect levels and unique photoelectricity properties, which are superior to their large single crystal and quantum dot counterparts ${ }^{6}$. For specific applications, the optical and electrical properties of nano/microwires can only be harnessed if long continuous nano/microwires can be synthesized. For example, ultralong microwires can be used as ultralow-loss conducting microcables or the integrated optical waveguide ${ }^{7-9}$. Until now, the growth of perovskite nano/microwires is reported by tremendous substrate-dependent methods. Spin/dip-coating precursor on a substrate and then to realize the growth of nano/microwires by anti-solvent or solvent evaporation methods are the most common approaches ${ }^{10}$. However, the unavoidable contamination and unevenness of the substrate can cause excess nucleation sites, which make the growth lack enough driving force 
and hamper the formation of ultralong perovskite microwires (PMWs) ${ }^{11}$. Besides, templateguided ${ }^{12}$, inkjet printing and roll-to-roll methods may be the promising technologies to achieve the design of ultralong microwires at the desired locations ${ }^{13,14}$, these materials often suffer from low crystal quality, which limited the device performance and the preparation technology is rather complicated. To overcome the above challenges, we introduce a facile substrate-free and low temperature crystallization approach to synthesizing high quality and ultralong (centimeter) $\mathrm{CH}_{3} \mathrm{NH}_{3} \mathrm{PbI}_{3} \mathrm{PMWs}$, which show a long carrier lifetime of $1775.7 \mathrm{~ns}$. Interestingly, the fabricated photodetection devices made from microwires have an ultralow dark current (2.5 fA) under $1 \mathrm{~V}$ bias and a high light on/off ratio of $1.79 \times 10^{6}$.

Almost all the previous growth methods of single crystal PMWs depend on the substrate by solvent evaporation or antisolvent crystallization (Table 1). These methods result in the formation of a supersaturated solution, which leads to more crystal nucleus on the substrate and the growth orientation and location of the microwires are always stochastic in nature ${ }^{15}$. Cooling adopted and substrate-free method, by contrast, show a great success in creating ultralong and freestanding $\mathrm{CH}_{3} \mathrm{NH}_{3} \mathrm{PbI}_{3} \cdot \mathrm{DMF}$ PMWs, as shown in Fig. 1a. In this synthesis route, the use of the polar aprotic solvent $N, N$-dimethylformamide (DMF) can effectively promote the anisotropic crystal growth to form a one-dimensional structure ${ }^{16}$. There are three regions about the relationship between supersaturation and spontaneous crystallization, more specifically, undersaturated zone, metastable zone and oversaturated zone. The key of crystal growth is to control the growth temperature and precursor concentration. Thus, the concentration of $\mathrm{CH}_{3} \mathrm{NH}_{3} \mathrm{PbI}_{3}$ perovskite solution concentration is controlled at $2.2 \mathrm{~mol} / \mathrm{L}$, and the growth temperature is controlled at room temperature (RT) to make the solution system enter the oversaturated region (see the supplementary materials for detailed synthesis method). In the oversaturated region, nucleation will spontaneously occur and seed crystals deposit to the bottom of the bottle under gravity. In order to make the growth details more vivid, $2 \mathrm{~mL}$ solution is used to synthesize the microwires (Fig. S1). The growth mechanism of the microwires is shown in Fig. 1b. Due to the strong coordination effects between perovskite precursors and solvents, DMF molecules combine with $\mathrm{PbI}_{2}$ to form one-dimensional (1D) structures of $\mathrm{PbI}_{2} \cdot \mathrm{DMF}{ }^{17}$. Subsequently, $\mathrm{PbI}_{2} \cdot \mathrm{DMF}$ reacts with $\mathrm{CH}_{3} \mathrm{NH}_{3} \mathrm{I}$ to form interphase-crystals $\mathrm{CH}_{3} \mathrm{NH}_{3} \mathrm{PbI}_{3} \cdot \mathrm{DMF}{ }^{18}$, which serve as seed crystals. In the metastable solution system, competitive growth will occur among precipitates when the seed crystals with various sizes are dispersed. This growth derives from the concentration gradients around the crystal particles caused by the thermodynamic behavior, which makes the whole system meets the surface energy is lowered as much as possible ${ }^{19}$. The longer PMWs grow upward at the cost of the dissolvent of smaller ones. To achieve the best crystallinity, there should be no interruption in 
the process of crystallization. From Fig. 1c, we observed the length of the microwire can be up to $7.6 \mathrm{~cm}$. Time course images are shown in Fig. S2. The growth of ultralong $\mathrm{CH}_{3} \mathrm{NH}_{3} \mathrm{PbI}_{3} \cdot \mathrm{DMF}$ microwires can reflect the high crystal quality, because if more defects are generated in the growth process, the periodicity of the lattice structure will be destroyed and the continuous growth will be terminated. Fig. 1d is the photo image of the as-grown single crystal microwires removed from the solution and the $\mathrm{CH}_{3} \mathrm{NH}_{3} \mathrm{PbI}_{3} \cdot \mathrm{DMF}$ is degraded into black $\mathrm{CH}_{3} \mathrm{NH}_{3} \mathrm{PbI}_{3}$ at the surface in air. Subsequently, we take out 50 perovskite microwires and calculated their average diameter and length as $90.08 \mu \mathrm{m}$ and $78.33 \mathrm{~mm}$, respectively (Fig. S3 and Fig. S4).

The single-crystal sample only has one set of diffraction pattern. Single crystal X-ray diffraction (XRD) shows that the white-microwires in the bottom have high crystal quality and belong to monoclinic system (Fig. 2a). The total molecular formula of the microwires is $\mathrm{C}_{4} \mathrm{H}_{13} \mathrm{I}_{3} \mathrm{~N}_{2} \mathrm{OPb}\left(\mathrm{CH}_{3} \mathrm{NH}_{3} \mathrm{PbI}_{3} \cdot \mathrm{DMF}\right)$ and DMF molecule is intercalated between $\left[\mathrm{Pb}_{2} \mathrm{I}_{6}\right]^{2-}$ layer and the $\mathrm{CH}_{3} \mathrm{NH}_{3}{ }^{+}$cation (Fig. S5). When we removed the microwires from DMF solvent, the DMF solvent molecules volatilize from the sample and transform into $\mathrm{CH}_{3} \mathrm{NH}_{3} \mathrm{PbI}_{3}$. Transmission electron micrograph image reveals a tetragonal crystal structure of the degraded microwires. The interplanar crystal distances measured from the high-resolution TEM image in Fig. $2 \mathbf{b}$ are $0.13 \mathrm{~nm}$ and $0.23 \mathrm{~nm}$, corresponding to the plane $(2 \overline{4} 2)$, and $(20 \overline{2})$, respectively ${ }^{20}$. The selected area electron diffraction (SAED) pattern (Fig. 2c) further confirms the crystalline nature of this $\mathrm{CH}_{3} \mathrm{NH}_{3} \mathrm{PbI}_{3}$ microwire. The powder XRD spectra of the microwires with degraded surfaces is show in Fig. S6, which is similar to the previously reported spectra of $\mathrm{CH}_{3} \mathrm{NH}_{3} \mathrm{PbI}_{3} \cdot \mathrm{DMF}{ }^{21}$. It should be emphasized that the characteristic peak of $\mathrm{CH}_{3} \mathrm{NH}_{3} \mathrm{PbI}_{3}$ is submerged because the degradation only occurs in the very shallow surface.

Cross-section energy dispersive X-ray spectroscopy (EDS) analysis exhibits a homogeneous distribution of each elementary (Fig. S7). The photoluminescence (PL) spectrum of the as-synthesized microwire is acquired with the excitation of $405 \mathrm{~nm}$ laser as shown in Fig. 2d. The PL spectrum has a symmetric narrow peak at $798 \mathrm{~nm}$ with a full width at half maximum (FWHM) of about $49.5 \mathrm{~nm}$, indicates the high crystalline quality of perovskite ${ }^{22}$. Fig. 2e shows the PL decay curve that was acquired by time correlated single photon counting (TCSPC) technique excited with a $405 \mathrm{~nm}$ picosecond pulsed laser. The PL signal lasts tens of microseconds indicating its very long lifetime. The PL decay curve can be well fitted by a triexponential function and three distinct components are extracted with $49.4 \mathrm{~ns}, 341.4 \mathrm{~ns}$ and $1775.7 \mathrm{~ns}$, respectively. In perovskite single crystal, the fast decay is ascribed to the surface component, the untreated external surface result in the fast PL decay component; the slow component originated from the bulk component (including bulk defect assisted trapping, 
bimolecular and Auger recombination) ${ }^{23,24}$. The long lifetime component is generally assigned as intrinsic recombination, up to $1.8 \mu \mathrm{s}$, indicating very low density of traps, as signposted by a longer lifetime ${ }^{25}$. Subsequently, the lifetime and length of as-prepared microwires and those of previously reported halide perovskite are shown in Fig. $\mathbf{2 f}$ (The performance parameters are also listed in Table S1 in the Supporting Information). Notably, the length and lifetime of asprepared microwires are about an order of magnitude larger than those of previously reported results. The longest carrier lifetime demonstrates that the obtained PMWs possess the least nonradiative recombination centers (text $\mathrm{S} 1$ ).

The schematic of the device structure and the crystal structure of the $\mathrm{CH}_{3} \mathrm{NH}_{3} \mathrm{PbI}_{3}$ are shown in Fig. 3a. For device fabrication, the middle segments of microwires was used and conducting silver paste was coated onto both ends of the PMWs (length: $1.93 \mathrm{~mm}$ ), constructing an ohmic-type device ${ }^{26}$. Fig. $3 \mathbf{b}$ depicts the current versus voltage (I-V) characteristics of the $\mathrm{CH}_{3} \mathrm{NH}_{3} \mathrm{PbI}_{3} \mathrm{PMWs}$-based device under dark and $808 \mathrm{~nm}$ light illumination from $45 \mu \mathrm{W} / \mathrm{cm}^{2}$ to $88 \mathrm{~mW} / \mathrm{cm}^{2}$, respectively. Dark current, which reflects the noise characteristics, is caused by surface or internal defects of the devices as well as harmful impurities (text S2). In this PMWsbased device, the measured dark current is just $2.5 \mathrm{fA}$ at the bias of $1 \mathrm{~V}$, which guarantees the device to operate under very weak optical signals by setting the low noise level of the photodetector. The dark current closely related to the defect state is called trap-assistant-tunnel current and the ultra-low dark current can be attributed to the high crystal quality (text S3) ${ }^{27}$.

Subsequently, visible light of the microscope is applied to verify the stability of the device. The dynamic stability experiment shows that the photocurrent did not decline significantly at the bias of $10 \mathrm{~V}$ (Fig. 3c), which shows relatively high repeatability under repeated light on/off switching cycles. The light illuminated continuously on the device for more than 10 minutes and then was withdrawn. The measurement results are shown in the Fig. 3d. The photocurrent is quite stable and then drop sharply as the light is turned off. It indicates a quick recombination of the carriers inside the materials and no remarkable accumulation of the carriers occurs. We monitored the degradation of the device by recording the photocurrent up to one month and found the photocurrent nearly kept constant in vacuum (Fig. 3e). Self-assembling test system is used for estimating the response speed as shown in the inset picture of Fig. 3f (see the supplementary materials for experimental details). Due to the fast charge generation and recombination, the rise and fall times can be calculated to be $0.18 \mathrm{~ms}$ and $0.28 \mathrm{~ms}$, respectively. The response time is comparable to the value of previous $\mathrm{CH}_{3} \mathrm{NH}_{3} \mathrm{PbI}_{3}$ perovskite network photodetector and much lower than the audiovisual reaction time (around $100 \mathrm{~ms})^{28}$.

Next, light to dark current ratio is extracted from the I-V curves at the bias of $1 \mathrm{~V}$, as shown in Fig. 3g. Increasing ratios arise from the fact that the conductance of the microwires increases 
with the increased light intensity. At the light intensity of $88 \mathrm{~mW} / \mathrm{cm}^{2}$, the on/off ratio can go up to $1.79 \times 10^{6}$, which is superior to that of the previously reported devices (See Table S2). We also calculate the figures of merit of responsivity (R) and detectivity ( $\left.D^{*}\right)$. Fig. 3h shows the values of $\mathrm{R}$ and $\mathrm{D}^{*}$ versus the incident light intensity ranging from $45 \mu \mathrm{W} / \mathrm{cm}^{2}$ to $88 \mathrm{~mW} / \mathrm{cm}^{2}$ at $1 \mathrm{~V}$ bias. Increasing the illumination intensity induces a decreased value, which is related to the increased possibility of carrier scattering and recombination ${ }^{29}$. Significantly, the calculated maximum $\mathrm{R}$ and $\mathrm{D}^{*}$ can up to $1.94 \times 10^{-4} \mathrm{~A} / \mathrm{W}$ and $4.85 \times 10^{10}$ Jones at the bias of $1 \mathrm{~V}$, respectively. The relative low responsivity can be attributed to the intrinsic characteristics of the microwires. In addition, the linear dynamic range (LDR) is calculated to be $125.03 \mathrm{~dB}$, which is comparable with that of Si photodetectors (120 dB) (Fig. S8). Detailed calculations for these parameters are given in the text S4. Fig. 3i shows that as-prepared device has the extremely low dark current among previously reported results. All the data presented here are obtained at the same bias of 1 V (see Table $\mathbf{S 2}$ for details). To characterize the device performance of the same microwire at different segments, the start, middle and end segments of the microwire $(\sim 2 \mathrm{~mm})$ typically used for device fabrication and device performance test are shown is Fig. S9. There were no significant differences of the devices fabricated by choosing different segments. The reasonable differences of device performance may be attributed to electrode preparation and length error caused by interception.

We further demonstrate the uniformity of the devices. Five microwires were taken out from the bottle and bonded to the printed circuit board (PCB) for fabricating the devices. The length is controlled to be approximately $1.24 \mathrm{~cm}$ as shown in Fig. 4a. Under visible light illumination $\left(2.33 \mathrm{~mW} / \mathrm{cm}^{2}\right)$, all devices exhibit similar photocurrent on the order of $10^{-9} \mathrm{~A}$ (Fig. 4b). This result confirms that the devices constructed from $\mathrm{CH}_{3} \mathrm{NH}_{3} \mathrm{PbI}_{3}$ microwires have a satisfactory uniformity. Slight dissimilitude of photocurrent of different devices can be attributed to the electrode preparation and diameter of microwires. In order to promote its flexible applications, another microwire $(\sim 1.5 \mathrm{~cm})$ is made into a detector and sealed with PDMS (Fig. 4c). The photocurrent is measured without bending and after several cycles of bending to a curvature radius of $5 \mathrm{~mm}$. Remarkably, it was observed that the device maintains operation status even after bend. The photocurrent of the device has a slightly changing after 300 cycles of bending (Fig. 4d), (see the supplementary text for experimental details) suggesting the flexibility of the device. The decline is mainly from fatigue process of the microwire caused by stress during cyclic loading and the damage once cracks form ${ }^{30}$.

In summary, we developed a unique strategy to synthesize up to $7.6 \mathrm{~cm}$ long free-standing perovskite microwires, which indicates the possibility of achieving high-quality PMWs breaking the previous length limitation. The device made from freestanding microwires has an 
ultralow dark current of $2.5 \mathrm{fA}$, which reflects the intrinsic characteristics of perovskite. As a result, our work has a significant potential impact on a wide range of electrical and photonic applications including lab-on-a-chip systems, micro cables and microprocessor.

\section{Experimental Section}

Materials. $\mathrm{CH}_{3} \mathrm{NH}_{3} \mathrm{I}(\geq 99.5 \%), \mathrm{PbI}_{2}(>99.99 \%)$ and $N, N$-Dimethylformamide with molecular sieves (DMF, $\geq 99.9 \%$ ) were purchased from Xi'an Polymer Light Technology Corp., 3A Chemicals and Aladdin. The PDMS was purchased from Dow Corning Corp.. All reagents were used as received without further purification.

Material growth and device fabrication. $\mathrm{CH}_{3} \mathrm{NH}_{3} \mathrm{I}(13.99 \mathrm{~g}, 88 \mathrm{mmol})$ and $\mathrm{PbI}_{2}(40.57 \mathrm{~g}, 88$ mmol) were dissolved in $40 \mathrm{~mL}$ DMF solvent under magnetic stirring at $80{ }^{\circ} \mathrm{C}$ to form transparent $\mathrm{CH}_{3} \mathrm{NH}_{3} \mathrm{PbI}_{3}$ perovskite solution $(2.2 \mathrm{~mol} / \mathrm{L})$ and then transferred into a bottle (diameter: $27.5 \mathrm{~mm}$, high: $95 \mathrm{~mm}$ ). Subsequently, place the bottle at room temperature without interruption. Seed crystals began to form three days later and the perovskite microwires (PMWs) would grow. After 12 days, the PMWs grew to the top of the solution with the height of $76 \mathrm{~mm}$. After the growth completed, the microwires were removed from the bottle. The devices were fabricated with silver paste at both ends of the microwires.

Materials characterization. To determine the lattice structure, the $\mathrm{CH}_{3} \mathrm{NH}_{3} \mathrm{PbI}_{3}$ PMWs samples were prepared firstly by using the focused ion beam (FIB) method. The equipment used was FIB precision sample preparation system (FEI Helios) and the prepared FIB slice was perpendicular to the growth direction. Subsequently, the transmission electron microscope (TEM) images and selected area electron diffraction (SAED) patterns were acquired from a TEM analysis system (main unit: FEI Tecnai F20) from FMMedia Technology Co., LTD.. The scanning electron microscopy (SEM) images and energy-dispersive X-ray (EDS) analysis images were obtained based on SEM analysis system (Zeiss Merlin) for observing the morphology and determining elemental composition of the samples, respectively. Photoluminescence (PL) spectra and time-resolved photoluminescence (TRPL) decays were performed on a microscopic fluorimeter system, where the hybrid perovskite was excited by a $405 \mathrm{~nm}$ picosecond diode laser $(62.5 \mathrm{kHz}$, pulse duration $50 \mathrm{ps})$. PL spectra were collected via a spectrometer (Ocean Optics, QE-Pro). TRPL was acquired via a time-correlated single-photon counting (TCSPC) module (PicoHarp 300). Crystal structure of the $\mathrm{CH}_{3} \mathrm{NH}_{3} \mathrm{PbI}_{3} \cdot \mathrm{DMF}$ microwire was directly solved by single crystal X-ray diffraction (XtaLAB PRO 007HF) and the software (CRYSALIS ${ }^{\text {pro }}$ ). To avoid degradation in air, the white microwires was taken out from the solution rapidly and cleaning the mother liquid with dimethicone. And then the sample 
with dimethicone is fixed on the test bench with an annular sleeve.

Photo-electrical measurements. The current-voltage and current-time curves were measured using a semiconductor parameter analyzer system (Agilent B1500A and Keithley 4200-SCS) except the dark I-V curve was directly measured using semiconductor parameter analyzer (FSPro) from Platform Design Automation. The $808 \mathrm{~nm}$ LED was used as the illumination source, and the light power density was measured with a light power meter (Thorlabs PM100D).

The response speed is an important figure of merit. In order to test the response speed of the device, two $4 \mathrm{~mm}$ microwires were connected in series with the battery pack $(8.4 \mathrm{~V})$, one of which acts as a series resistance and the other as a detection device. The $808 \mathrm{~nm}$ LED was connected with the signal generator (SP F20) to provide $1 \mathrm{kHz}$ pulse light for the device. At the same time, the digital oscilloscope (Agilent DSO-X 3024A) was used to record the highfrequency photoelectric signal of the device.

To test the flexibility, the device was encapsulated with PDMS and the part of silver paste was exposed as the electrode. The probe was electrically connected with the electrode, and the photocurrent was measured by the Keithley 2636B. The number of bends was manually controlled with the frequency less than $1 \mathrm{~Hz}$. To ensure that each bend has the same radius of curvature (5 mm), both ends of PDMS are slight contact (Fig. S10). 
a

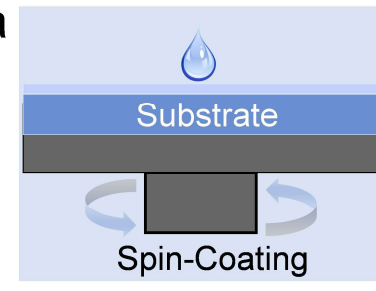

$\mathrm{b}$

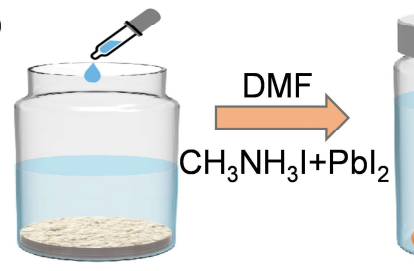

C . . . $: \mathrm{Pbl}_{2}$

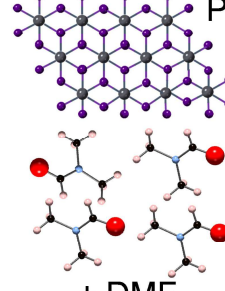

$+\mathrm{DMF}$

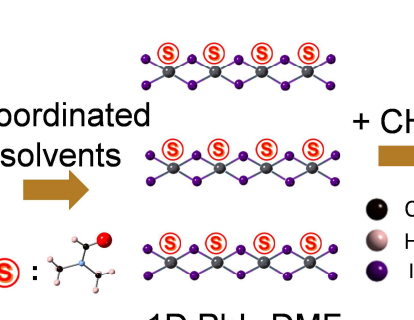

1D $\mathrm{Pbl}_{2} \cdot \mathrm{DMF}$

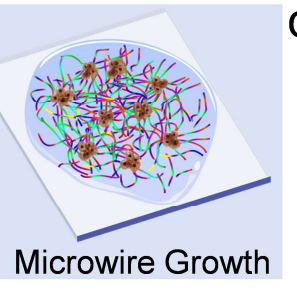

Dip-Coating

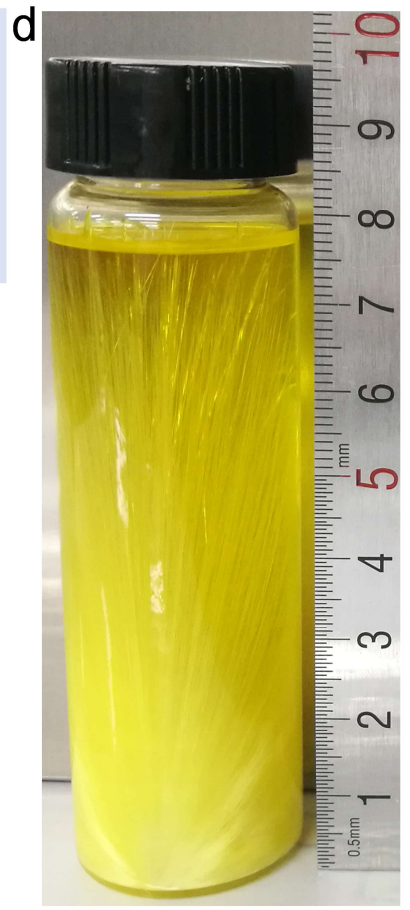

e

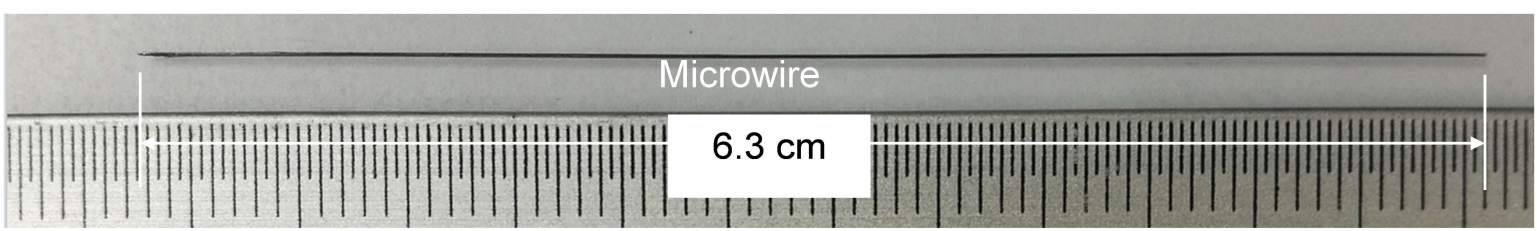

Fig. 1| Preparation and characterization of PMWs. a, Low temperature crystallization method proposed in this work with ultralong PMWs and $\mathbf{b}$, Schematic of growth mechanism of microwires. c, Photograph of $\mathrm{CH}_{3} \mathrm{NH}_{3} \mathrm{PbI}_{3} \cdot \mathrm{DMF}$ PMWs growth, which has already stopped growing. d, As-grown ultralong perovskite microwire. 

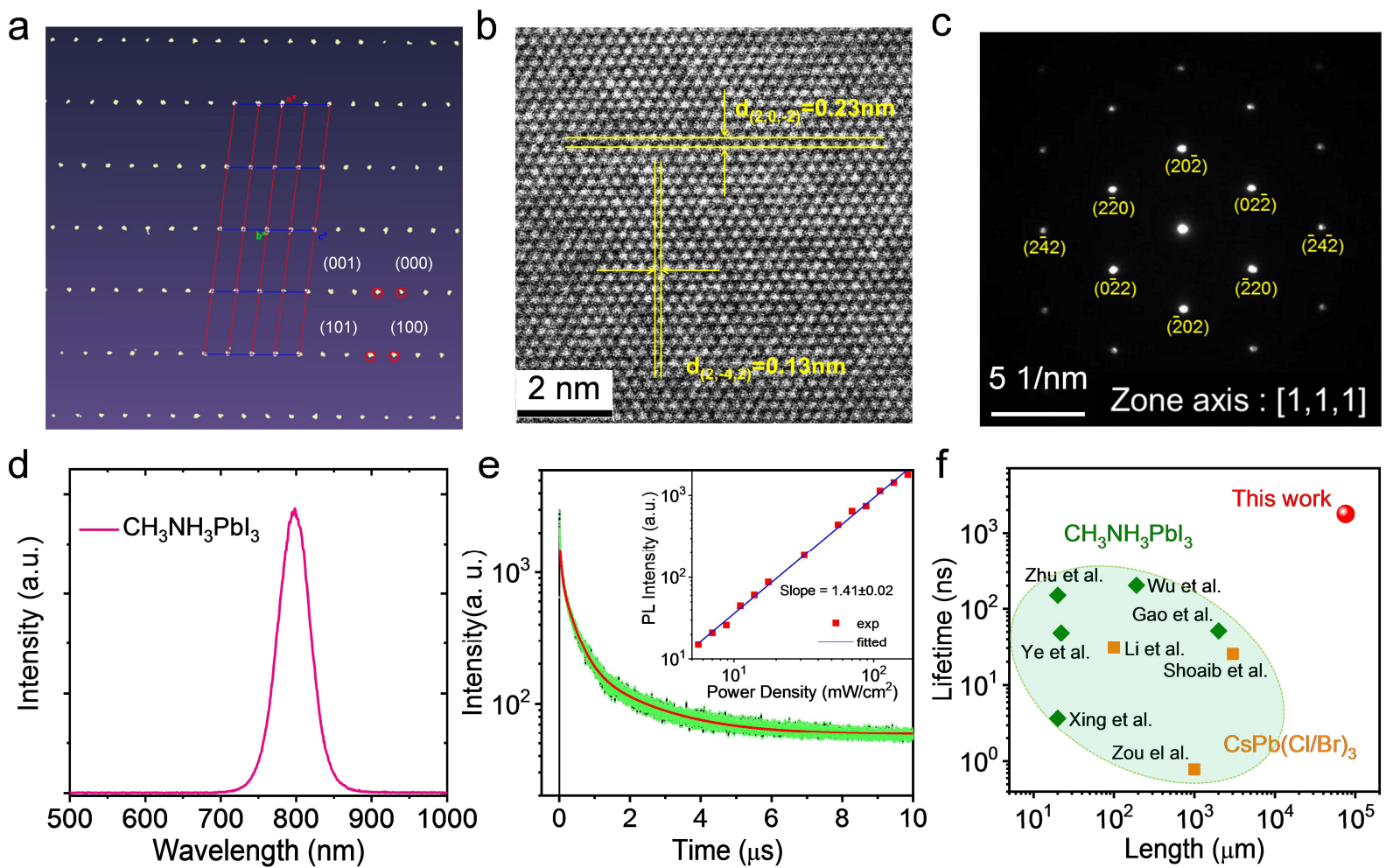

Fig. 2| Characterization of as-prepared PMWs. a, The XRD resluts of $\mathrm{CH}_{3} \mathrm{NH}_{3} \mathrm{PbI}_{3} \cdot \mathrm{DMF}$ single crystal inside the solution. b, c, High-resolution TEM image and SAED pattern of $\mathrm{CH}_{3} \mathrm{NH}_{3} \mathrm{PbI}_{3} \mathrm{PMWs}$ after taking out from the solution, respectively. $\mathbf{d}$, A PL spectrum of PMWs $\left(\lambda_{\text {exc }}=405 \mathrm{~nm}\right)$. e, TRPL spectrum of PMWs under the excitation of picosecond pulse laser $\left(\lambda_{\text {exc }}=405 \mathrm{~nm}\right)$ at $405 \mathrm{~nm}$. f, Comparison of the lifetime and length of the as-prepared PMWs with other perovskite materials reported previously. 

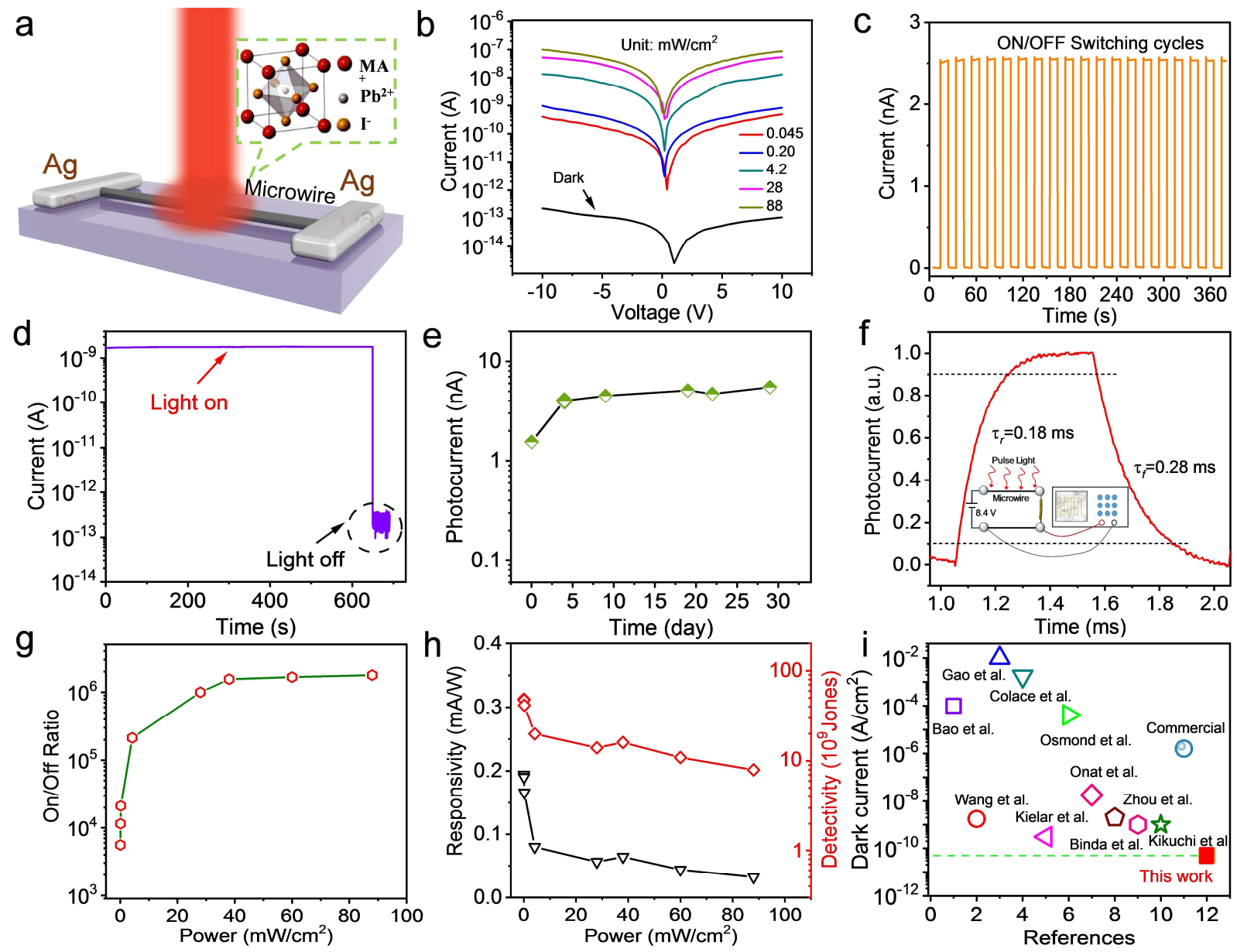

Fig. 3| Photodetection performance of $\mathrm{CH}_{3} \mathrm{NH}_{3} \mathrm{PbI}_{3}$ PMWs-based device. a, Schematic of the device structure. $\mathbf{b}, \mathrm{I}-\mathrm{V}$ curves of the device in dark and under light illumination at $808 \mathrm{~nm}$ with different light intensities. c, Photo-switching I-T curve under alternating dark and light illumination of $0.53 \mathrm{~mW} / \mathrm{cm}^{2}$. d, I-T curve under $10 \mathrm{~min}$ of continuous light illumination $(0.39$ $\mathrm{mW} / \mathrm{cm}^{2}$ ) at $10 \mathrm{~V}$ bias. e, Photocurrent of the device under the light intensity of $0.39 \mathrm{~mW} / \mathrm{cm}^{2}$ for up to one month. f, Response speed of the device (insert: response test system). $\mathbf{g}$, Light to dark current ratio at the bias of $1 \mathrm{~V}$. h, Responsivity and detectivity under different light intensity. i, Comparison of the dark current of the as-prepared device with other devices reported previously. 

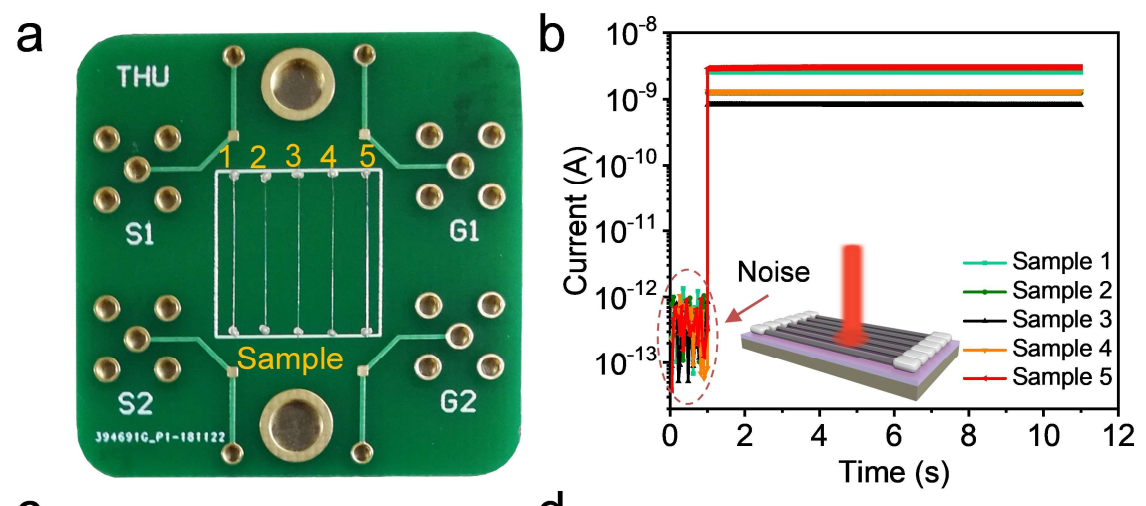

C

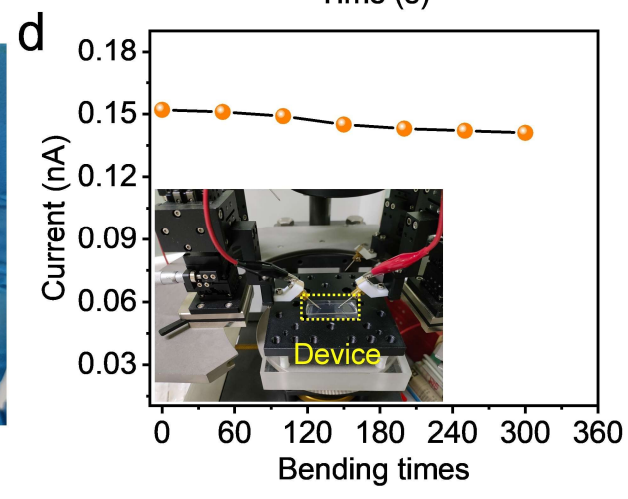

Fig. 4| Uniformity and bending robustness of $\mathrm{CH}_{3} \mathrm{NH}_{3} \mathrm{PbI}_{3} \mathrm{PMWs}$-based devices. a, Photograph of the devices bonded on PCB. b, Photocurrent of different devices under the same illumination. c, Photograph of the device encapsulated in the flexible PDMS. d, Photocurrent of the encapsulated device with different bending cycles at bias of 10 $\mathrm{V}$ under the visible light intensity of $154.7 \mu \mathrm{W} / \mathrm{cm}^{2}$. Experimental equipment is shown in the insert. 
Table 1. Comparison of growth characteristics of microwires prepared by traditional and optimized growth methods.

\begin{tabular}{c|c|c|c}
\hline & \multicolumn{2}{|c|}{ Traditional } & This work \\
\hline $\begin{array}{c}\text { Synthetic } \\
\text { Method }\end{array}$ & Solvent Evaporation & $\begin{array}{c}\text { Antisolvent } \\
\text { Crystallization }\end{array}$ & $\begin{array}{c}\text { Low Temperature } \\
\text { Crystallization }\end{array}$ \\
\hline Substrate & Need & Need & No need \\
\hline $\begin{array}{c}\text { Relative } \\
\text { Merits }\end{array}$ & $\begin{array}{c}\text { Arrayable, } \\
\text { Length-limited }(\mu \mathrm{m}- \\
\mathrm{cm})\end{array}$ & $\begin{array}{c}\text { Arrayable, } \\
\text { Length-limited }(\mu \mathrm{m}-\end{array}$ & $\begin{array}{c}\text { Ultralong (up to 7.6 } \\
\mathrm{cm}), \text { Controllable, } \\
\mathrm{cm})\end{array}$ \\
\hline
\end{tabular}

\section{Additional information}

Supporting Information is available from the online version of the paper or from the author.

\section{Acknowledgements}

This work was supported by the National Key R\&D Program (2016YFA0200400) and National Natural Science Foundation (62022047, 61874065, 51861145202) of China. The authors are also thankful for the support from Beijing Innovation Center for Future Chip, Tsinghua University and the Independent Research Program of Tsinghua University (20193080047). He Tian thanks for the support from Young Elite Scientists Sponsorship Program by CAST (2018QNRC001) and Fok Ying-Tong Education Foundation (Grant No. 171051). We thank Baohua Jia from Swinburne University of Technology for assistance with PL and TRPL measurements. All authors would like to thank Renrong Liang for his support of TEM measurements.

\section{Author contributions}

Geng X, Feng Q, and Tian H contributed equally to this work. Geng X designed experiments, synthesized ultralong perovskite microwires. Geng X, Chen W, Wen X, Jia B, Wang C, and $\mathrm{Wu} X$ characterized materials. Geng X, and Feng Q fabricated and characterized devices. Geng X, Dun G, Ren J, Wang F, and Yan Z wrote the manuscript. Dun G, Deng N, Zhang H, and Li C provided measurement support. Tian $\mathrm{H}$, Xie D, and Yang Y provided theoretical guidance. Ren T-L and Tian H supervised the project and put forward specific amendments. 


\section{References}

1. Kojima, A., Teshima, K., Shirai, Y. \& Miyasaka, T. Organometal halide perovskites as visible-light sensitizers for photovoltaic cells. J. Am. Chem. Soc. 131, 6050-6051 (2009).

2. Liu, Y., Yang, Z. \& Liu, S. F. Recent progress in single-crystalline perovskite research including crystal preparation, property evaluation, and applications. Adv. Sci. 5, 1700471 (2018).

3. Dong, H., Zhang, C., Liu, X., Yao, J. \& Zhao, Y. S. Materials chemistry and engineering in metal halide perovskite lasers. Chem.Soc.Rev. 49, 951-982 (2020).

4. Li, C., Liu, Z., Shang, Q. \& Zhang, Q. Surface-plasmon-assisted metal halide perovskite small lasers. Adv. Optical Mater. 7, 1900279 (2019).

5. Stranks, S. D. et al. Electron-hole diffusion lengths exceeding 1 micrometer in an organometal trihalide perovskite absorber. Science 342, 341-344 (2013).

6. Deng, W. et al. Aligned single-crystalline perovskite microwire arrays for highperformance flexible image sensors with long-term stability. Adv. Mater. 28, 2201-2208 (2016).

7. Zhu, H. W. et al. Direct synthesis of long single-walled carbon nanotube strands. Science 296, 884-886 (2002).

8. Bao, Q. et al. Polarized emission and optical waveguide in crystalline perylene diimide microwires. Adv. Mater. 22, 3661-3666 (2010).

9. Hills, G. et al., Modern microprocessor built from complementary carbon nanotube transistors. Nature 572, 595-602 (2019).

10. Horvath, E. et al. Nanowires of methylammonium lead iodide $\left(\mathrm{CH}_{3} \mathrm{NH}_{3} \mathrm{PbI}_{3}\right)$ prepared by low temperature solution-mediated crystallization. Nano. Lett. 14, 6761-6766 (2014).

11. Chen, S. et al. Aerosol assisted chemical vapour deposition of conformal $\mathrm{ZnO}$ compact layers for efficient electron transport in perovskite solar cells. Mater. Lett., 217, 251-254 (2018).

12. Xu, X., Zhang, X., Deng, W., Jie, J. \& Zhang, X. 1D organic-inorganic hybrid perovskite micro/nanocrystals: fabrication, assembly, and optoelectronic applications. Small Methods 2, 1700340 (2018).

13. Liu, Y. et al. Inkjet-printed photodetector arrays based on hybrid perovskite $\mathrm{CH}_{3} \mathrm{NH}_{3} \mathrm{PbI}_{3}$ microwires. ACS Appl. Mater. Interfaces 9, 11662-11668 (2017).

14. $\mathrm{Hu}, \mathrm{Q}$. et al. Large-area perovskite nanowire arrays fabricated by large-scale roll-to-roll micro-gravure printing and doctor blading. Nanoscale 8, 5350-5357 (2016).

15. Deng, W. et al. Ultrahigh-responsivity photodetectors from perovskite nanowire arrays for 
sequentially tunable spectral measurement. Nano. Lett. 17, 2482-2489 (2017).

16. Im, J. H. et al. Nanowire perovskite solar cell. Nano Lett. 15, 2120-2126 (2015).

17. Wakamiya, A. et al. Reproducible fabrication of efficient perovskite-based solar cells: Xray crystallographic studies on the formation of $\mathrm{CH}_{3} \mathrm{NH}_{3} \mathrm{PbI}_{3}$ Layers. Chem. Lett. 43, 711713 (2014).

18. Hao, F., Stoumpos, C. C., Liu, Z., Chang, R. P. H. \& Kanatzidis, M. G. Controllable perovskite crystallization at a gas-solid interface for hole conductor-free solar cells with steady power conversion efficiency over 10\%. J. Am. Chem. Soc. 136, 16411 (2014).

19. Baldan, A. Review progress in ostwald ripening theories and their applications to nickelbase superalloys Part I: Ostwald ripening theories. J. Mater. Sci. 37, 2171-2202 (2002).

20. Luan, M., Song, J., Wei, X., Chen, F. \& Liu, J. Controllable growth of bulk cubic-phase $\mathrm{CH}_{3} \mathrm{NH}_{3} \mathrm{PbI}_{3}$ single crystal with exciting room-temperature stability. CrystEngComm 18, 5257-5261 (2016).

21. Ozaki, M. et al. A Purified, Solvent-intercalated precursor complex for wide-process window fabrication of efficient perovskite solar cells and modules. Angew. Chem. Int. Ed. 58, 9389- 9393 (2019).

22. Segovia, R. et al. Effect of phase transition stress on the photoluminescence of perovskite $\mathrm{CH}_{3} \mathrm{NH}_{3} \mathrm{PbI}_{3}$ microwires. J. Mater. Sci. 54, 5331-5342 (2018).

23. Shi, D. et al. Low trap-state density and long carrier diffusion in organolead trihalide perovskite single crystals. Science 347, 519-522 (2015).

24. Grancini G. et al. $\mathrm{CH}_{3} \mathrm{NH}_{3} \mathrm{PbI}_{3}$ perovskite single crystals: surface photophysics and their interaction with the environment. Chem. Sci. 6, 7305 (2015).

25. Liu, Y. et al. A $1300 \mathrm{~mm}^{2}$ ultrahigh-performance digital imaging assembly using highquality perovskite single crystals. Adv. Mater. 30, 1707314 (2018).

26. Wu, Y., Yang, R., Tian, H. \& Chen, S. Photoelectric characteristics of $\mathrm{CH}_{3} \mathrm{NH}_{3} \mathrm{PbI}_{3} / \mathrm{p}-\mathrm{Si}$ heterojunction. J. Semicond. 37, 053002 (2016).

27. Wang, J. et al. Temperature dependence characteristics of dark current for arsenic doped LWIR HgCdTe detectors. Infrared Phys. Techn. 61, 157-161 (2013).

28. Deng, H. et al. Flexible and semitransparent organolead triiodide perovskite network photodetector arrays with high stability. Nano. Lett. 15, 7963-7969 (2015).

29. Boruah, B. D., Mukherjee, A. \& Misra, A. Sandwiched assembly of $\mathrm{ZnO}$ nanowires between graphene layers for a self-powered and fast responsive ultraviolet photodetector. Nanotechnology 27, 095205 (2016).

30. Bai, Y. et al. Super-durable ultralong carbon nanotubes. Science 369, 1104-1106 (2020). 


\title{
Electronic Supplementary Material
}

\section{Ultralong free-standing single crystal perovskite microwires with extremely low dark current}

\begin{abstract}
Xiangshun Geng ${ }^{1}$, Qixin Feng ${ }^{1}$, He Tian ${ }^{1, *}$, Weijian Chen ${ }^{2}$, Xiaoming Wen ${ }^{2}$, Baohua Jia ${ }^{2}$, Chaolun Wang ${ }^{3}$, Xing $\mathrm{Wu}^{3}$, Guanhua Dun ${ }^{1}$, Jun Ren ${ }^{1}$, Ningqin Deng ${ }^{1}$, Fangwei Wang ${ }^{1}$, Zhaoyi Yan ${ }^{1}$, Hainan Zhang ${ }^{1}$, Cheng $\mathrm{Li}^{4}$, Yi Yang ${ }^{1, *}$, Dan Xie ${ }^{1, *}$, Tian-Ling Ren ${ }^{1, *}$

${ }^{1}$ School of Integrated Circuits and Beijing National Research Center for Information Science and Technology (BNRist), Tsinghua University, Beijing 100084, China;

${ }^{2}$ Centre for Translational Atomaterials, School of Science, Swinburne University of Technology, Hawthorn Victoria 3122, Australia;

${ }^{3}$ Shanghai Key Laboratory of Multidimensional Information Processing, School of Communication and Electronic Engineering, East China Normal University, 500 Dongchuan Road, Shanghai, 200241, China.

${ }^{4}$ School of Instrumentation Science and Opto-Electronics Engineering, Beihang University, Beijing 100191, China.

*Email: Rent1@tsinghua.edu.cn, tianhe88@tsinghua.edu.cn, yiyang@tsinghua.edu.cn, xiedan@tsinghua.edu.cn
\end{abstract}

\section{Supplementary Text}

\section{$\underline{\text { Text S1. Defect properties }}$}

The defect properties of perovskites analysed by a fluence-dependent steady-state PL intensity measurement is shown in Fig. S11. The spot size is larger than the diameter of microwires. PL quantum yield of halide perovskites depends closely on the competition between radiative recombination (bimolecular) and nonradiative recombination (defect assisted and Auger). That is, with increasing excitation intensity, PL quantum yield increases in the low excitation regime. We measured the PL intensity as a function of excitation fluence. The PL intensity exhibits a super-linear dependence with increasing excitation fluence in double-logarithmic coordinates, which is ascribed to the increased weight of bimolecular radiative recombination with increasing fluence.

Such a featured super-linear PL is interpreted using the theory of defect state filling effect. PL intensity can be expressed as the total excitation fluence minus nonradiative recombination, as Auger recombination is negligible at the regime of low excitation. The incremental in PL intensity with increasing excitation fluence can be expressed as ${ }^{1}$ :

$$
\Delta I_{P L}=C \eta \sigma I_{E x} \cdot\left(1+f_{\mathrm{s}}\right) \cdot \Delta I_{E x}
$$

where $I_{E x}, \eta, \sigma$ are the excitation fluence, detection efficiency and absorption cross section of the samples, respectively; $\mathrm{C}$ is a constant and $f_{\mathrm{s}}$ is the filling factor of the defects, which is correlated with the excitation fluence and relaxation rates of the defect states. 
The slope of 1.41 is obtained, significantly smaller than that previously obtained in $\mathrm{MAPbI}_{3}$ (e.g., 1.8) and $\mathrm{MAPbI}_{3}$ by CVD (relative lower defect density of 1.6), indicating low defect trapping in the microwires ${ }^{2,3}$.

To further validate the TRPL results, we measured excitation-fluence dependent PL decays of the PMWs in supplement fluence range $\left(9-90 \mathrm{~mW} / \mathrm{cm}^{2}\right)$. As shown in Fig. S12, with increasing excitation fluence, the sample exhibits an evident decrease of PL lifetime, which is the dynamic process that defect saturates at higher excitation laser fluence, and bimolecular recombination of charge carriers significantly increases. Note that the defects are easily saturated at this range of low excitation power, therefore further confirmed the low trap densities observed.

\section{Text S2. Noise current}

The total current noise of the device includes the $1 / \mathrm{f}$ noise, shot noise, and thermal noise. The $1 / \mathrm{f}$ noise, which mainly origin from the process of carrier capture and de-capture, can be expressed as the following equation:

$$
N_{t}=\left(\frac{\int I_{f} d t}{q}\right)^{2} \frac{2 k}{A K_{b} T}(1 H z)
$$

where $N_{t}, I_{f}, q, K_{b}, A, k$ and $T$ are the trap density, the $1 / f$ noise, the elementary charge, Boltzmann's constant, the device area, the tunneling transmission coefficient, and the device temperature. An effective way to reduce the noise is to improve the crystal quality and thus to decrease the trap density. The shot noise can be expressed as: $i_{\mathrm{s}}=\left(2 q I_{\mathrm{d}} B\right)^{1 / 2}$, where $\mathrm{I}_{\mathrm{d}}$ is the dark current and $\mathrm{B}$ is the bandwidth. Besides, the thermal noise is given by $i_{l}=\left(4 K_{b} T B / R\right)^{1 / 2}$, where $\mathrm{R}$ is the resistance of the device. We found that the total noise current can be reduced by increasing the device resistance, reducing the crystal defect and decreasing the device area.

\section{$\underline{\text { Text S3. Dark current }}$}

The dark current mainly includes diffusion current, generation-recombination (G-R) current, trap-assistant-tunnel (T-A-T) current and band-to-band (B-T-B) current, the expression of TA-T current is as follows:

$$
\mathrm{I}_{\text {tat }}=-\mathrm{A} \cdot \frac{\pi^{2} q^{2} N_{t} m_{e}^{*} M^{2}\left(V_{b i}-V_{d}\right)}{h^{3}\left(E_{g}-E_{t}\right)} \exp \left(-\frac{\sqrt{3} E_{g}^{2} F(a)}{8 \sqrt{2} q P E}\right)
$$

where $\mathrm{N}_{\mathrm{t}}$ is the trap density, $\mathrm{m}_{\mathrm{e}}{ }^{*}$ is the electron effective mass, $\mathrm{E}_{\mathrm{g}}$ is the bandgap energy, $\mathrm{P}$ is the Kane matrix element, $M$ is the transition matrix element between the trap level and conduction band. Therefore, dark current is intimately correlated to the defect density in halide perovskites. 


\section{$\underline{\text { Text S4. Device performance }}$}

Responsivity, the net photocurrent generated per unit power of the incident light, indicates the detector's ability to convert optical signal into photocurrent. It can be expressed as,

$$
R=\frac{I_{p}-I_{d}}{A P_{\text {in }}}
$$

where $I_{p}$ is the photocurrent, $I_{d}$ is the dark current, $A$ is the effective area, and $P_{\text {in }}$ is the incident optical power density. At the bias of $1 \mathrm{~V}, \mathrm{R}=\left(1.40 \times 10^{-11} \mathrm{~A}-2.51 \times 10^{-15} \mathrm{~A}\right) /\left(0.0016 \mathrm{~cm}^{2} \times 0.045\right.$ $\left.\mathrm{mW} / \mathrm{cm}^{2}\right)=1.94 \times 10^{-4} \mathrm{~A} / \mathrm{W}$.

Detectivity is given by

$$
D^{*}=\frac{R}{\left(2 q J_{d}\right)^{1 / 2}}
$$

where $\mathrm{R}$ is the responsivity, $\mathrm{q}$ is the electron charge, and $\mathrm{J}_{\mathrm{d}}$ is the dark current density. At the bias of $1 \mathrm{~V}, \mathrm{D}^{*}=\left(1.94 \times 10^{-4} \mathrm{~A} / \mathrm{W}\right) /\left(2 \times 1.60 \times 10^{-19} \mathrm{C} \times 5.01 \times 10^{-11} \mathrm{~A} / \mathrm{cm}^{2}\right)^{1 / 2}=4.85 \times 10^{10}$ Jones $\left(\right.$ Jones $\left.=\mathrm{cm} \cdot \mathrm{Hz}^{1 / 2} \cdot \mathrm{W}^{-1}\right)$.

Linear dynamic range (LDR) is usually used to describe the linear characteristics of the variation of photocurrent with light intensity in a certain range. It can be expressed as,

$$
L D R=20 \log \frac{I_{p}}{I_{d}}
$$

where $I_{p}$ is the photocurrent, $I_{d}$ is the dark current. At the bias of $1 \mathrm{~V}, \mathrm{LDR}=20 \times \log \left(4.48 \times 10^{-}\right.$ $\left.9 / 2.51 \times 10^{-15}\right)=125.03 \mathrm{~dB}$.

Response speed, which including rise time and fall time, is another import figure of merit. Rise time is defined as the time experienced from $10 \%$ to $90 \%$ peak value, while fall time is defined as the time experienced from $90 \%$ to $10 \%$ peak value. In this work, the rise time and fall time are calculated to be $0.18 \mathrm{~ms}$ and $0.28 \mathrm{~ms}$, respectively. 

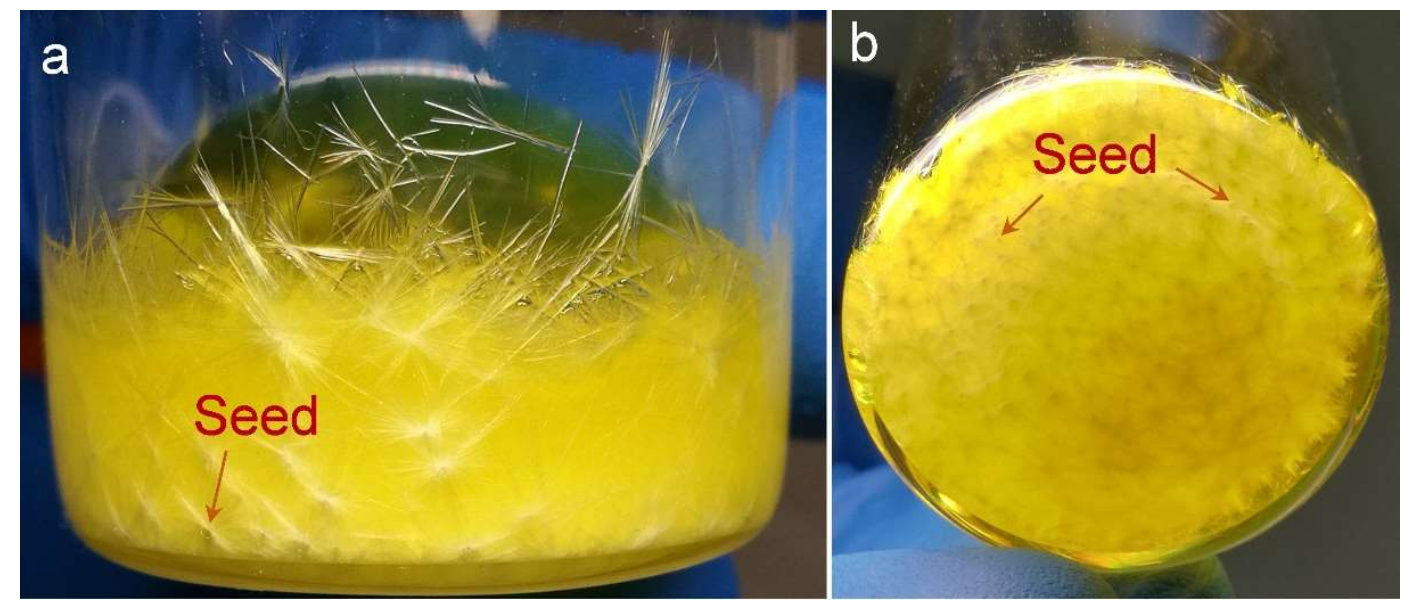

Figure S1. Growth mechanism of free-standing perovskite microwires. a, The front view and $\mathbf{b}$, upward view of the material growth indicates that the microwires begin to grow at the position of the seed crystals. In order to study the growth mechanism of PMWs, $2 \mathrm{~mL}$ $\mathrm{CH}_{3} \mathrm{NH}_{3} \mathrm{PbI}_{3}$ perovskite solution was dropped into the bottle and additional slight shaking can cause the perovskite solution stick to the wall of the bottle. After 3 days, many seeds can be seen at the bottom of the bottle. The nucleation rate can be expressed as follow:

$$
N \propto \exp \left(-\frac{\Delta G+b}{K_{b} T}\right)
$$

where $K_{b}$ is Boltzmann constant, $\Delta G$ is the activation free energy, $b$ is a constant and $T$ is the growth temperature ${ }^{4}$. 


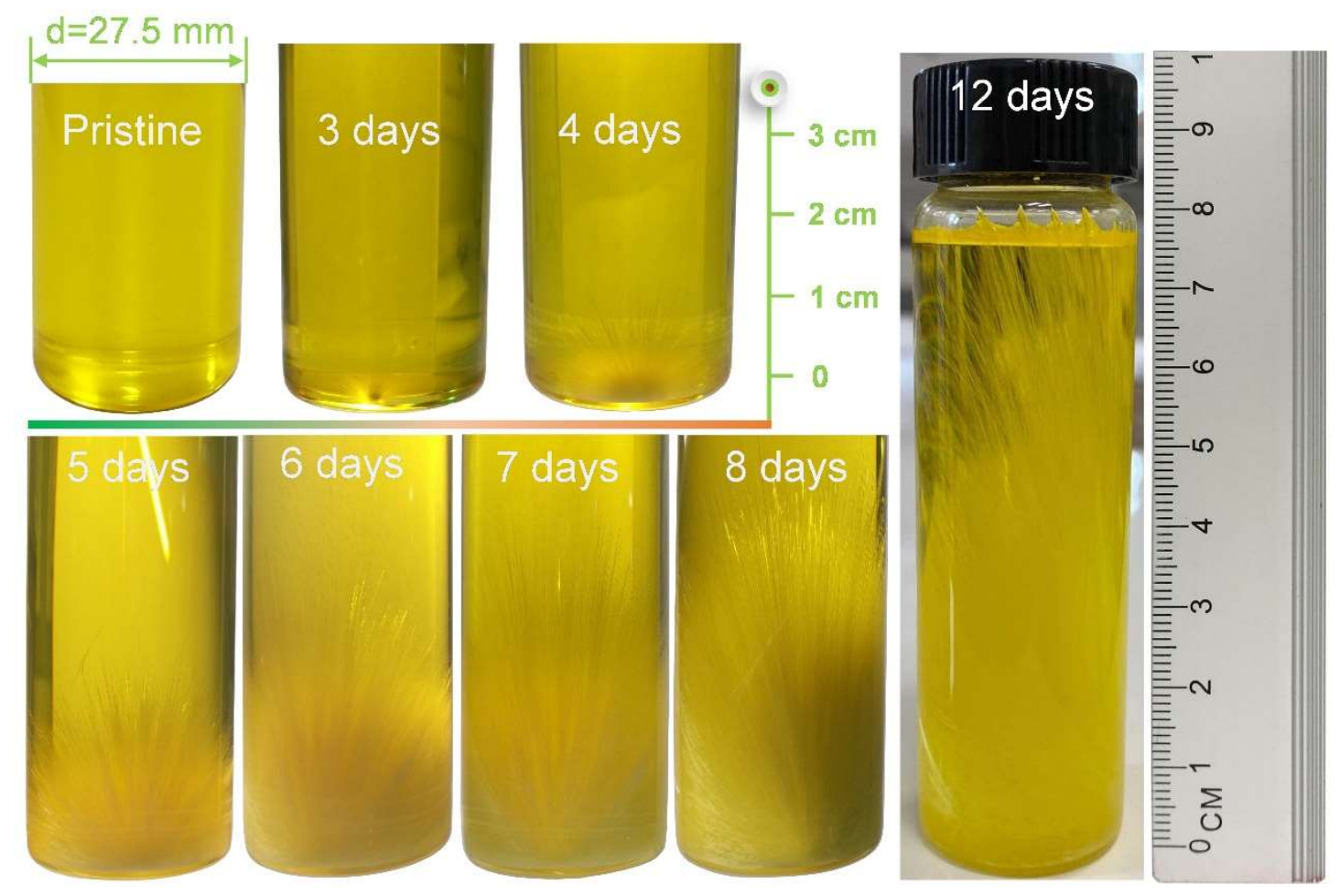

Figure S2. Time course images of the growth of perovskite microwires. From the time course images, we can find that crystal seeds are formed on the 3rd day, and then the microwires grow continuously with the average growth rate of $\sim 0.87 \mathrm{~cm} /$ day at the seeds position. Finally, the microwires stop growing at the top of the solution and get the same length approximately as shown in the last picture. 


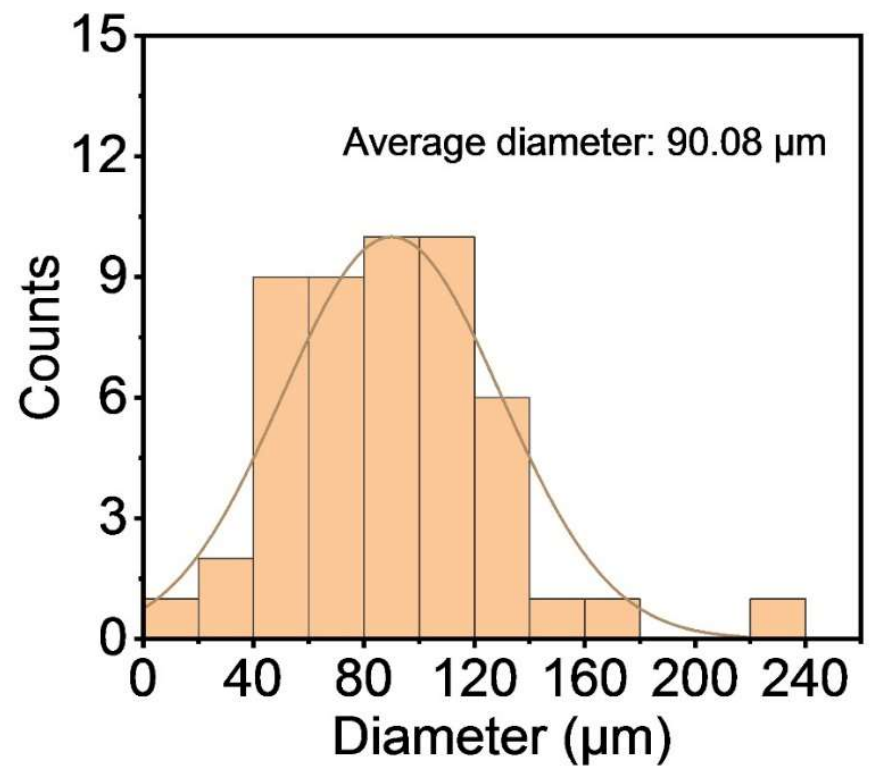

Figure S3. The statistic distribution of perovskite microwires diameters. According to the statistics, the diameters of 50 microwires are from $18.56 \mu \mathrm{m}$ to $238.85 \mu \mathrm{m}$ and mainly distributed from $40 \mu \mathrm{m}$ to $140 \mu \mathrm{m}$. The average diameter is $90.08 \mu \mathrm{m}$, which shows Gaussian distribution. The standard deviation is calculated to be $39.20 \mu \mathrm{m}$. 


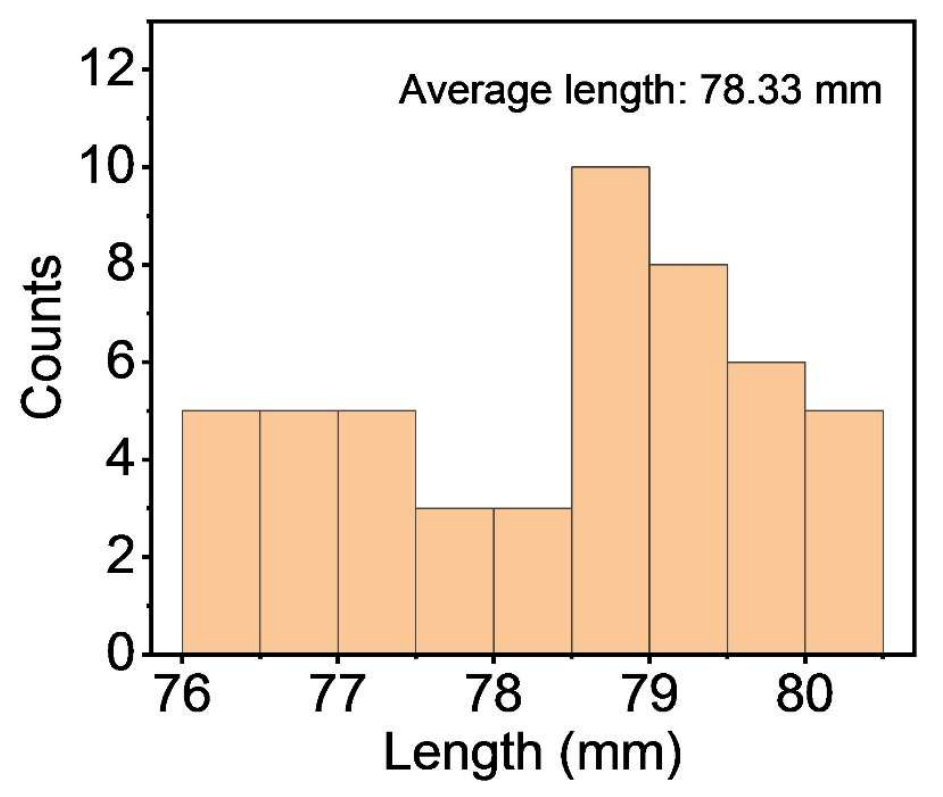

Figure S4. The statistic distribution of perovskite microwires length. According to the statistics, the average length of 50 microwires is $78.33 \mathrm{~mm}$ and the standard deviation is 1.25 $\mathrm{mm}$. 


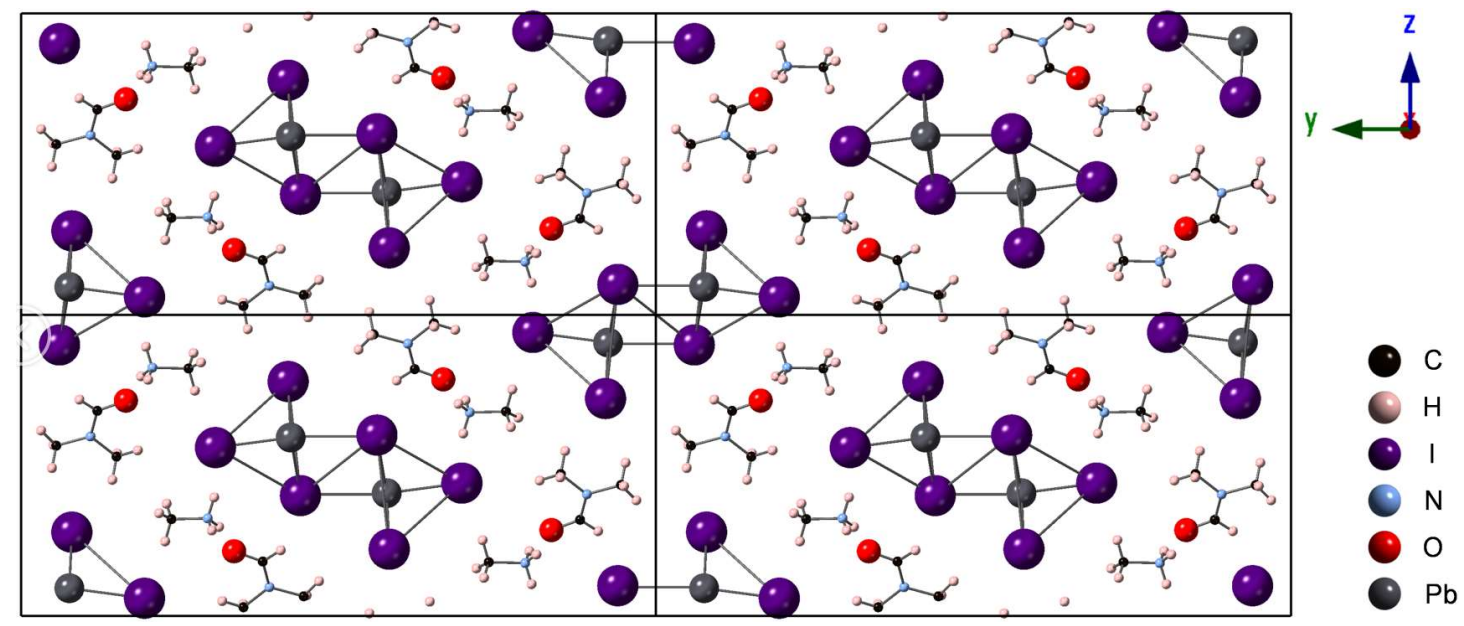

Figure S5. Single-crystal structure of $\mathrm{CH}_{3} \mathrm{NH}_{3} \mathrm{PbI}_{3} \cdot \mathrm{DMF}$. The crystal data are as follows: $a=4.5571(2) \AA, b=25.3631(7) \AA, c=12.1214(4) \AA, \alpha=90.000^{\circ}, \beta=96.534(3)^{\circ}, \gamma=90.000^{\circ}$, Monoclinic, $\mathrm{P} 2{ }_{1} / \mathrm{c}$. 


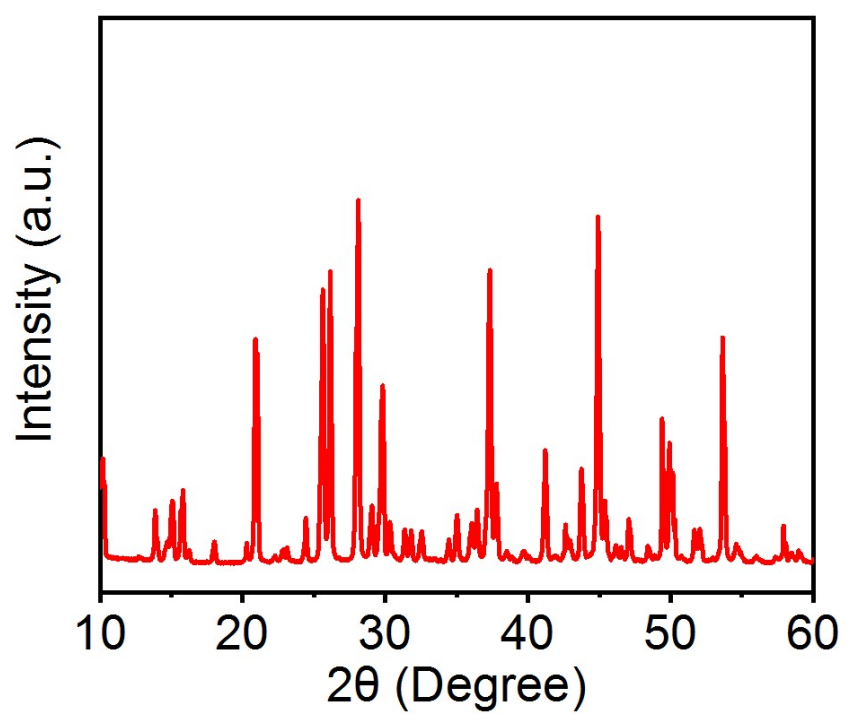

Figure S6. Powder XRD spectra of the microwires with degraded surfaces. 


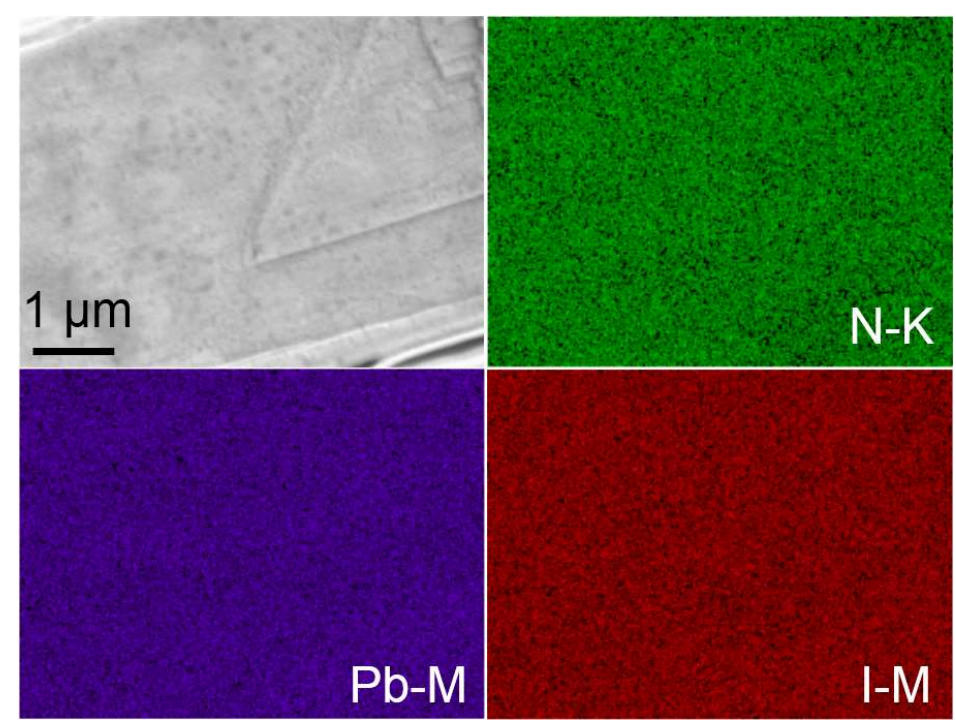

Figure S7. Element mapping image of PMWs. EDS analysis exhibits a homogeneous distribution for $\mathrm{N}, \mathrm{Pb}$, I elementary. 


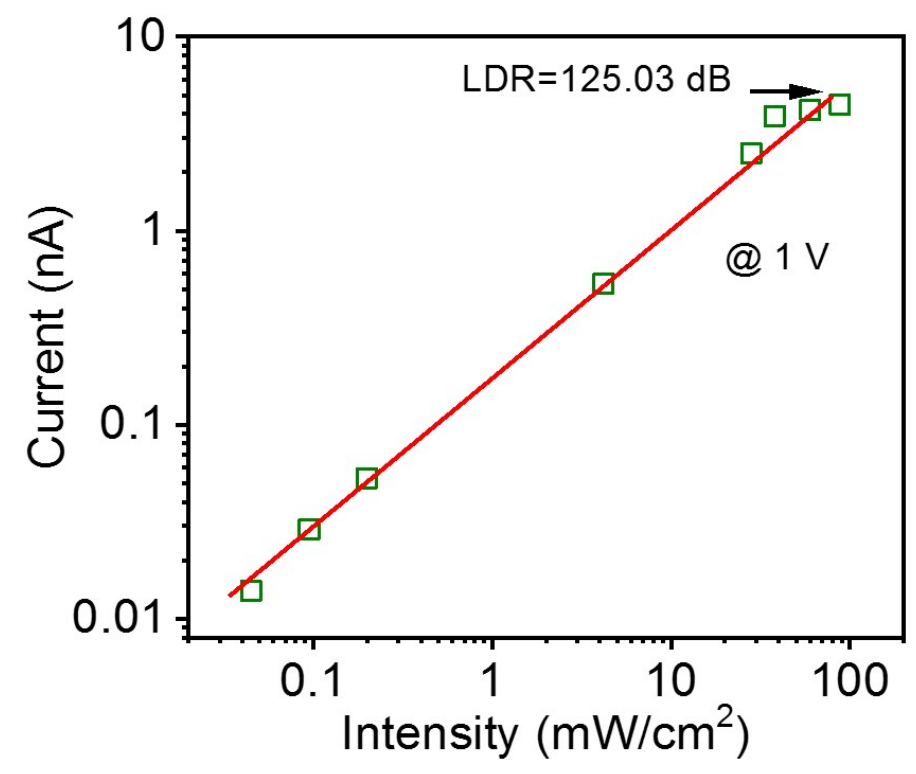

Figure S8. Photocurrent versus light intensity of the perovskite microwires detector under $808 \mathbf{~ n m}$ light illumination. At the bias of $1 \mathrm{~V}$, the LDR is calculated to be $125.03 \mathrm{~dB}$. 


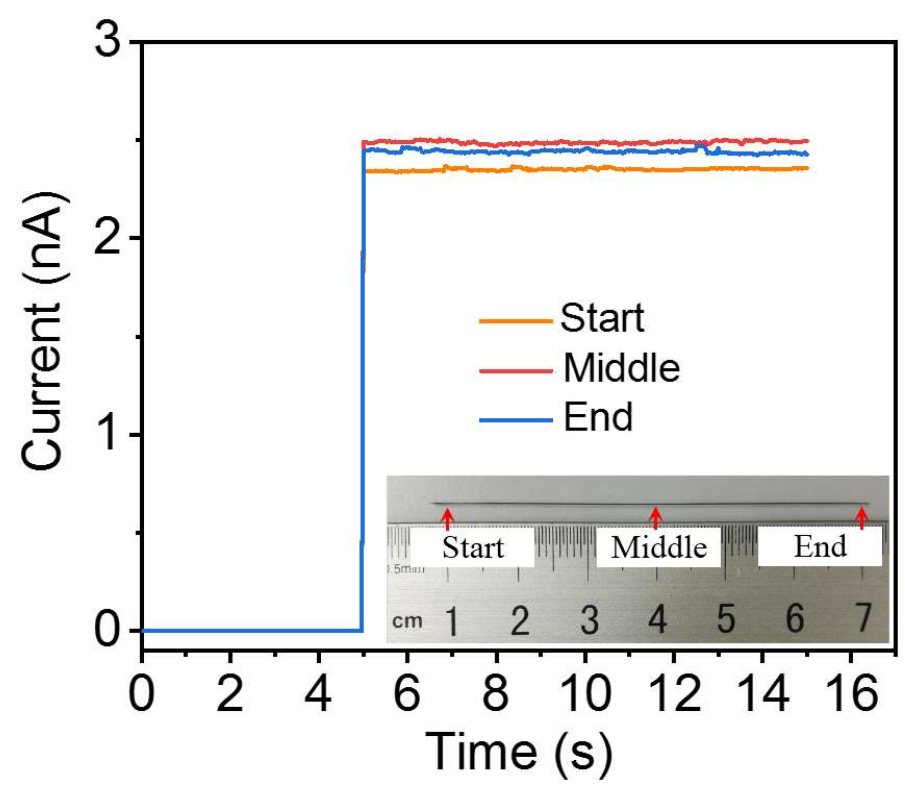

Figure S9. The performance of devices prepared by using same microwire in different segments. Start segment: the position from $9 \mathrm{~mm}$ to $1.1 \mathrm{~cm}$. Middle segment: the position from $3.9 \mathrm{~cm}$ to $4.1 \mathrm{~cm}$. End segment: the position from $6.9 \mathrm{~cm}$ to $7.1 \mathrm{~cm}$. 


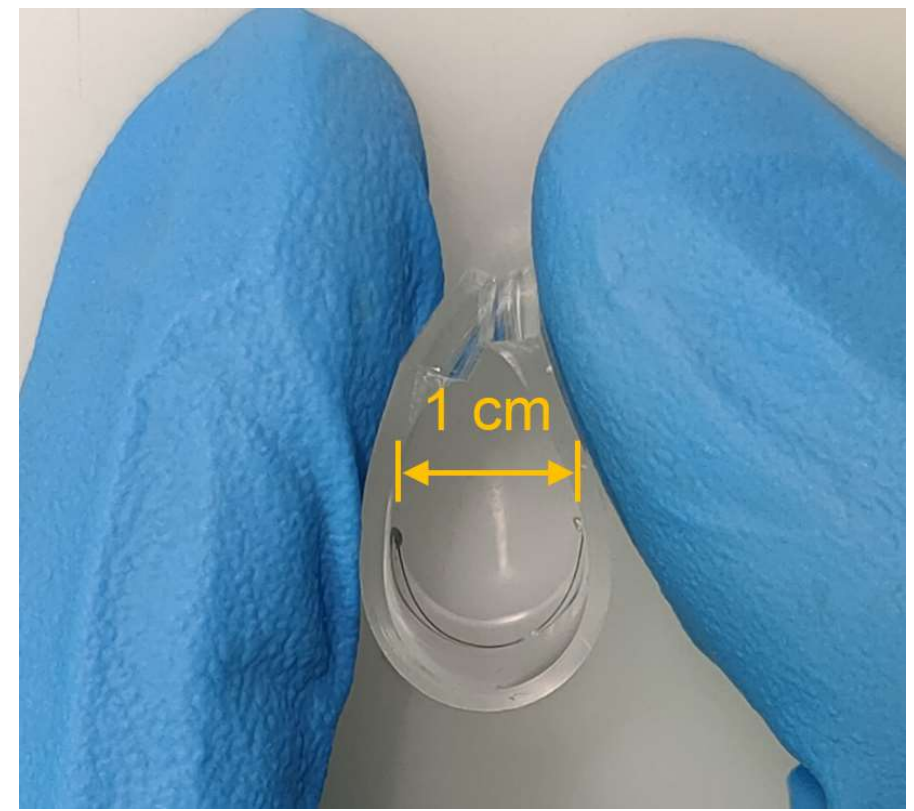

Figure S10. Flexible testing of the detector. The curvature radius of bending is controlled at $5 \mathrm{~mm}$. 


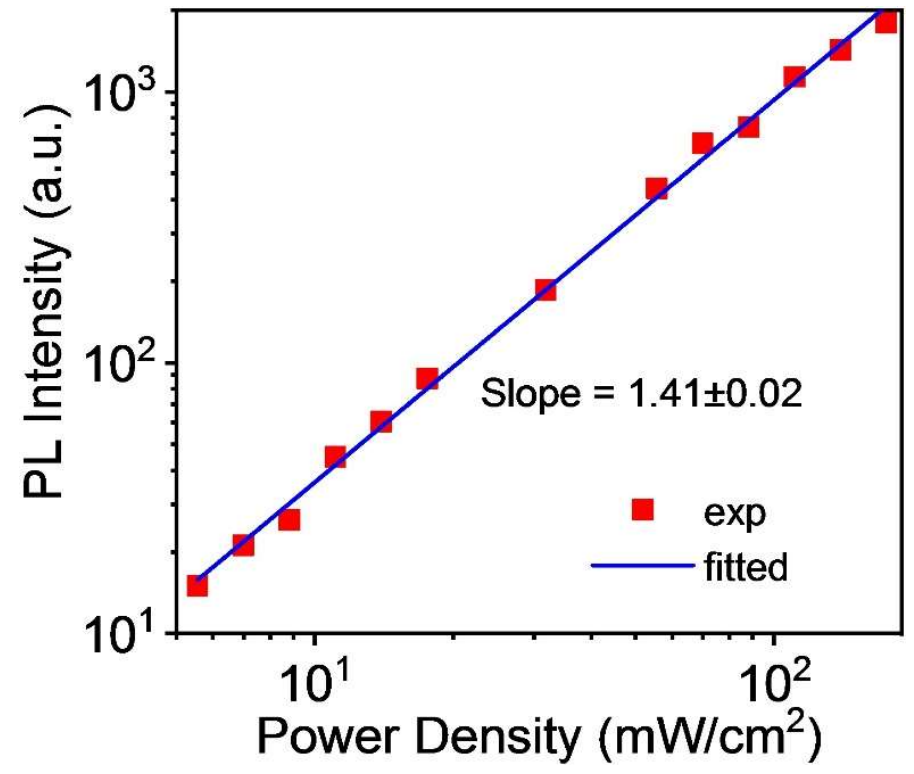

Figure S11. Power Dependent PL Intensity. The small slope of 1.41 indicates low defect trapping in the PMWs. 


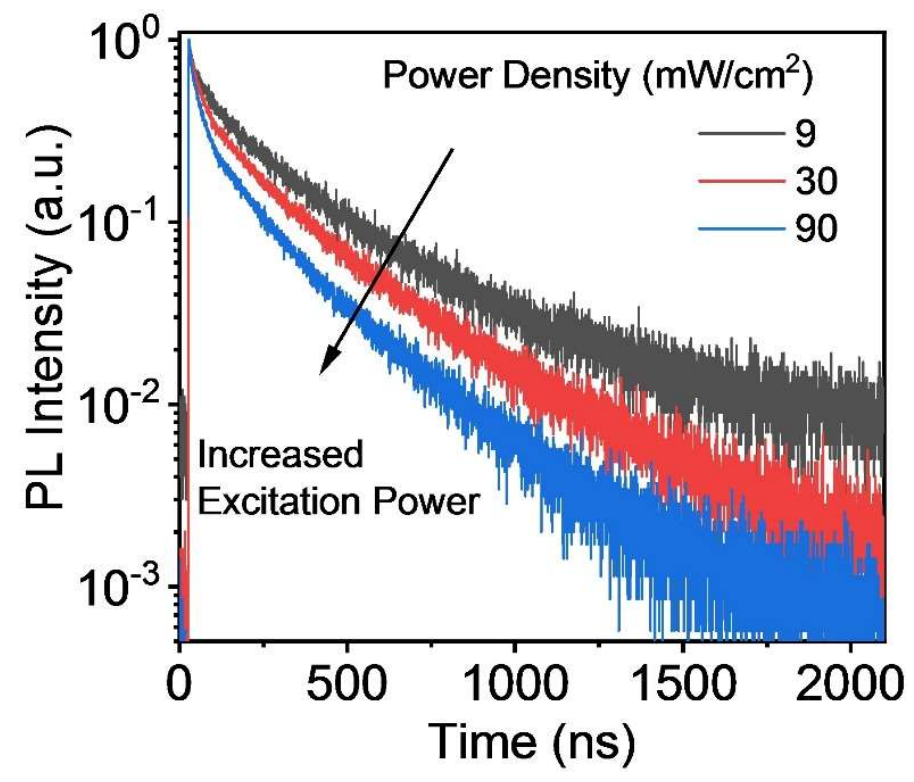

Figure S12. Power dependent TRPL decay traces. The excitation-fluence dependent PL decays of the PMWs in supplement fluence range $\left(9-90 \mathrm{~mW} / \mathrm{cm}^{2}\right)$. 
Table S1. Length and corresponding lifetimes of as-prepared $\mathrm{CH}_{3} \mathrm{NH}_{3} \mathrm{PbI}_{3}$ microwires and those of related halide perovskite microwires. The length of the microwire prepared by temperature-controlled growth method is significantly longer than that of other growth methods, and in view of the superior crystal quality, as-prepared microwire shown a very long carrier lifetime.

\begin{tabular}{|c|c|c|c|}
\hline Materials & Length & Lifetime & Ref. \\
\hline $\mathrm{CH}_{3} \mathrm{NH}_{3} \mathrm{PbI}_{3}$ & $>76 \mathrm{~mm}$ & $1775.7 \pm 17.9 \mathrm{~ns}$ & This work \\
\hline $\mathrm{CH}_{3} \mathrm{NH}_{3} \mathrm{PbI}_{3}$ & $190.7 \pm 39.1 \mu \mathrm{m}$ & $202.5 \mathrm{~ns}$ & 5 \\
\hline $\mathrm{CH}_{3} \mathrm{NH}_{3} \mathrm{PbI}_{3}$ & $22 \mu \mathrm{m}$ & $48.12 \mathrm{~ns}$ & 6 \\
\hline $\mathrm{CH}_{3} \mathrm{NH}_{3} \mathrm{PbI}_{3}$ & $\sim 20 \mu \mathrm{m}$ & $150 \mathrm{~ns}$ & 7 \\
\hline $\mathrm{CH}_{3} \mathrm{NH}_{3} \mathrm{PbI}_{3}$ & $20 \mu \mathrm{m}$ & $\sim 3.7 \mathrm{~ns}$ & 8 \\
\hline $\mathrm{CH}_{3} \mathrm{NH}_{3} \mathrm{PbI}_{3}$ & $2 \mu \mathrm{mm}$ & $51.3 \mathrm{~ns}$ & 9 \\
\hline $\mathrm{CH}_{3} \mathrm{NH}_{3} \mathrm{PbBr}_{3}$ & $10 \mu \mathrm{m}$ & - & 10 \\
\hline $\mathrm{CH}_{3} \mathrm{NH}_{3} \mathrm{PbBr}_{3}$ & $36.01 \mu \mathrm{m}$ & - & 11 \\
\hline $\mathrm{CsPb}_{2} \mathrm{Cl}_{3} \mathrm{Br}_{3}$ & $\sim 1 \mathrm{~mm}$ & $\sim 0.78 \mathrm{~ns}$ & 12 \\
\hline $\mathrm{CsPbBr}$ & $<3 \mathrm{~mm}$ & $25.23 \mathrm{~ns}$ & 13 \\
\hline $\mathrm{CsPbCl}$ & $<100 \mu \mathrm{m}$ & $30.5 \mathrm{~ns}$ & 14 \\
\hline
\end{tabular}


Table S2. Performance comparison with other devices, and our device has the extremely low dark current, which reflects the intrinsic property. The light on/off ratio is higher than most reported optoelectronic devices.

\begin{tabular}{|c|c|c|c|}
\hline Materials & $\begin{array}{c}\text { Idark }_{\text {dark }} \\
\left(\mathrm{A} / \mathrm{cm}^{2}\right)\end{array}$ & $\mathbf{I}_{\mathbf{o n}} / \mathbf{I}_{\mathbf{o f f}}$ & Reference \\
\hline $\mathrm{MAPbI}_{3} \mathrm{MWs}$ & 5E-11@1V & $1.79 \mathrm{E} 6$ & This work \\
\hline $\mathrm{MAPbI}_{3} \mathrm{TSC}$ & >1E-4@1V & - & 15 \\
\hline $\mathrm{CH}_{3} \mathrm{NH}_{3} \mathrm{PbI}_{3} / \mathrm{C}_{60}$ & 1.75E-9@-1V & $<1 \mathrm{E} 3$ & 16 \\
\hline $\mathrm{MAPbI}_{3} \mathrm{NWs}$ & 〜1E-2@1V & 250 & 9 \\
\hline $\mathrm{Ge} / \mathrm{Si}$ & 1.75E-3@1V & $3 \mathrm{E} 4$ & 17 \\
\hline Organic PCDTBT & -3.1E-10@-1V & $\sim 1 \mathrm{E} 6$ & 18 \\
\hline $\mathrm{Ge} / \mathrm{Si}$ & 4.1E-5@-1V & - & 19 \\
\hline $\mathrm{InGaAs}$ & $1.8 \mathrm{E}-8 @-1 \mathrm{~V}$ & - & 20 \\
\hline Squaraine/PC ${ }_{61} \mathrm{BM}$ & 2E-9@1 V & - & 21 \\
\hline Poly-TPD & 1E-9@-1V & $<1 \mathrm{E}-4$ & 22 \\
\hline $\mathrm{Ga}_{2} \mathrm{O}_{3} / \mathrm{CuInGaSe} \mathrm{Iu}_{2}$ & 1E-9@1V & - & 23 \\
\hline InGaAs-FGA21 & 1.6E-6@1V & - & Commercial \\
\hline
\end{tabular}




\section{Supplementary References}

1. Wen, X. et al. Role of surface recombination in halide perovskite nanoplatelets. ACS Appl. Mater. Interfaces 10, 31586-31593 (2018).

2. Wen, X. et al. Defect trapping states and charge carrier recombination in organicinorganic halide perovskites. J. Mater. Chem. C 4, 793-800 (2016).

3. Wen, X. et al. Role of surface recombination in halide perovskite nanoplatelets. ACS Appl. Mater. Interfaces 10, 31586-31593 (2018).

4. Gao, R. et al. Carrier lifetime exceeding $81 \mathrm{~ns}$ in single crystalline perovskite nanowires enable large on-off ratio photodetectors. Org. Electron. 83, 105744 (2020).

5. Wu, X., Wang, J. \& Yeow, E. K. L. Ultralong perovskite microrods: one- versus two-step synthesis and enhancement of hole-transfer during light soaking. The $J$. Phys. Chem. C 120, 12273-12283 (2016).

6. Ye, Q. et al. Wet-chemical synthesis of surface-passivated halide perovskite microwires for improved optoelectronic performance and stability. ACS. Appl. Mater. Interfaces 10, 43850-43856 (2018).

7. Zhu, H. et al. Lead halide perovskite nanowire lasers with low lasing thresholds and high quality factors. Nat. Mater. 14, 636-642 (2015).

8. Xing, J. et al. Vapor phase synthesis of organometal halide perovskite nanowires for tunable room-temperature nanolasers. Nano. Lett. 15, 4571-4577 (2015).

9. Gao, L. et al. Passivated single-crystalline $\mathrm{CH}_{3} \mathrm{NH}_{3} \mathrm{PbI}_{3}$ nanowire photodetector with high detectivity and polarization sensitivity. Nano. Lett. 16, 7446-7454 (2016).

10. Zhuo, S., Zhang, J., Shi, Y., Huang, Y. \& Zhang, B. Self-template-directed synthesis of porous perovskite nanowires at room temperature for highperformance visible-light photodetectors. Angew. Chem. Int. Ed. Engl .54, 5693$5696(2015)$.

11. Wang, K. et al. High-density and uniform lead halide perovskite nanolaser array on silicon. J. Phys. Chem. Lett. 7, 2549-2555 (2016).

12. Zou, S. et al. Template-free synthesis of high-yield Fe-doped cesium lead halide perovskite ultralong microwires with enhanced two-photon absorption. J. Phys. Chem. Lett. 9, 4878-4885 (2018). 
13. Shoaib, M. et al. Directional growth of ultralong $\mathrm{CsPbBr}_{3}$ perovskite nanowires for high-performance photodetectors. J. Am. Chem. Soc. 139, 15592-15595 (2017).

14. Li, Y. et al. Controllable vapor-phase growth of inorganic perovskite microwire networks for high-efficiency and temperature-stable photodetectors. ACS Photonics 5, 2524-2532 (2018).

15. Bao, C. et al. Low-noise and large-linear-dynamic-range photodetectors based on hybrid-perovskite thin-single-crystals. Adv. Mater. 29, 1703209 (2017).

16. Wang, Y. et al. $\mathrm{CH}_{3} \mathrm{NH}_{3} \mathrm{PbI}_{3} / \mathrm{C}_{60}$ heterojunction photodetectors with low dark current and high detectivity. Org. Electron. 42, 203-208 (2017).

17. Colace, L., Ferrara, P., Assanto, G., Fulgoni, D. \& Nash, L. Low dark-current germanium-on-silicon near-infrared detectors. IEEE Photonics Technol. Lett. 19, 1813-1815 (2007).

18. Kielar, M., Dhez, O., Pecastaings, G., Curutchet, A. \& Hirsch, L. Long-term stable organic photodetectors with ultra low dark currents for high detectivity applications. Sci. Rep. 6, 39201 (2016).

19. Osmond, J. et al. Ultralow dark current $\mathrm{Ge} / \mathrm{Si}(100)$ photodiodes with low thermal budget. Appl. Phys. Lett. 94, 201106 (2009).

20. Andresen, B. F. et al. Ultra-low dark current InGaAs technology for focal plane arrays for low-light level visible-shortwave infrared imaging, Infrared Technology and Applications XXXIII, 6542, 65420L (2007).

21. Binda, $M$. et al. High detectivity squaraine-based near infrared photodetector with nA $/ \mathrm{cm}^{2}$ dark current. Appl. Phys. Lett. 98, 073303 (2011).

22. Zhou, X., Yang, D. \& Ma, D. Extremely low dark current, high responsivity, allpolymer photodetectors with spectral response from $300 \mathrm{~nm}$ to $1000 \mathrm{~nm}$. Adv. Opt. Mater. 3, 1570-1576 (2015).

23. Kikuchi, K. et al. Photocurrent multiplication in $\mathrm{Ga}_{2} \mathrm{O}_{3} / \mathrm{CuInGaSe} \mathrm{Ce}_{2}$ heterojunction photosensors. Sensor Actuat. A-Phys. 224, 24-29 (2015). 